\title{
Prepaid Electricity Making Easier or Causing Households Problems: An Approach To Increase Customer Desires
}

\author{
Putu Hari Kurniawan ${ }^{1}$ Renniwaty Siringoringo ${ }^{2}$ \\ \{harifebby@gmail.com ${ }^{1}$ \} \\ ${ }^{1,2}$ Faculty Of Business Putera Batam University, Indonesia
}

\begin{abstract}
In this paper we explore prepaid electricity program is also one of the strategies for improving the image and corporate reputation. The purpose of this study was to measure the level of trust public service corporate given to the prepaid electricity program conducted by PT PLN Bright Batam as measured by the variable customer value and its implications for the image of PT PLN Bright Batam as a public company. The research population customers prepaid household electricity in 7districts with a sample take from of 200 respondents. Sampling techniques using Proportional sampling techniques. This research used explanatory survey to analyze the relationship between customer value and trust in the company's image. The result of this study indicate all variable manifested is fit through latent variable customer value, trust and image corporate has positive effect for all manifest variable analysis. The results suggest that the program needs to be made convenient for low income and elderly households. Accompanying the program with additional information on energy savings might also help make the program more effective and efficient. The analytical used Structural Equation Model (SEM) analysis with the Lisrel for Windows version 9.3
\end{abstract}

Keywords: Customer value; Customer trust; Image corporate; Prepaid Electricity

\section{Introduction}

Developed information technology is changing rapidly, it was requiring various companies to give proper and fast solutions according to the needs and desires of the customers, so customers could be satisfied and loyal in the future. Today's in modern life society marketing pattern has shifted, not just creating transactions to make success in sales and companies must also set up relationships with customers for a long term. In the other hand likewise PT PLN Bright Batam as State Owner Enterprises sells electrical energy I to serve household and manufactures explain gaining profit from the business. It's no longer relies on sales volume, but satisfaction oriented were applied in any conditions. Prepaid Electricity is one of the innovations based on information technology which aims to improve services and streamline customers in terms for using and getting electricity. 
Prepaid Electricity is one of the innovations based on information technology which aims to improve services and streamline customers in terms of using and getting electricity. Prepaid electricity planned came from the weakness of post-paid electricity, such as errors in reading the meter, bills that are not appropriate with usage, delinquency accounts and termination of electricity have a negative impact in the customers' mind. From the customer case, the Prepaid Electricity program helps customers to regulate and control their own electricity usage, so that customers can save electricity regularly. Prepaid electricity savings contribute to the amount of electricity that was saved so that more Indonesian citizens be served by electricity. In addition, prepaid electricity a strategy to improve image and reputation the corporate, which it starts from the corporate analysis of customer complaints furthermore.

From the primary survey informed error prepaid electricity occur while amount charges being low in customers meter indicator, the problems take place in Batam were many prepaid customers complain.. The event of a power outage the meter panel is zero after the blackout, while at the time before the balance out there is still contained a bill. The second problem policy of electricity tariff increase that was officially imposed by PT Bright Batam in March 2017 also contributed to the public complain. Based on the governor regulation, PT Bright Batam imposes a new first-rate tariff for several groups. In the other hand, the application of prepaid electricity only targets low-income communities where high- income people are not sympathetic to this program because inefficient.

[1] in empirical research found that to create customer trust and customer satisfaction, companies were able to increase customer value. Suggests that customer value is a trade-off between customer perceptions of the quality or benefits of the product and the sacrifice made through the price paid. Customer value created through often service provided by the company to its customers. The service quality can motivate the customer value the company more competitive. Based from research [2] It was found that the implementation of an effective price scheme was implemented which was applied to the low and middle-income segments in Bangladesh. From this study, it was found that the application of the price scheme in Bangladesh is suitable for all types of segmentation in Bangladesh. Price schemes that are made effective were applied in the economic household in the poverty community so they are able to reduce monthly bills. But on the other hand investment in the development of facilities has been temporarily delayed but electricity supply has become smoothly sustainable.Further research [3] compared the success rates of prepaid electricity promotions in several countries such as Britain and South Africa. Technology diversification in the two countries provides guidance on prepaid electricity services in Brazil so as to prevent abuse of electricity in the country, one of the advantages is that the Brazilian people have the freedom to migrate between payment systems

From the two studies, it is expected that future research will emphasize more on improving prepaid electricity services, especially the lower and middle segments in developing countries

PT Bright Batam as a public company runs an electrical energy distribution business customers need to support the company's image corporate. The negative implications occur the problem can reduce customer customer trust to the company, which will ultimately reduce the company's image corporate in customers mind. 


\section{Methodology}

\subsection{Customer Value}

[4] suggests that customer value is a trade-off between customer perception of the quality or benefits the product and the sacrifice made through the price paid whereas Butz \& Goodstein (1996) confirms that customer value is the emotional bond between the customer and the manufacturer after the customer uses the product or service produced by the supplier, and finds that the product concerned provides added customer [5]. Meanwhile [6] define customer value as perceptual preferences and customer evaluations of product attributes, performance attributes, and consequences obtained from the use of products that ease meet the goals and aims of customers in situations. From the above explanations concluded that consumers directly or indirectly will asses customer needs that provided the product. Evaluation based on the overall assessment between received and experienced which compared to expect. [7].

\subsection{Customer Trust}

Customer trust is a company's willingness to depend on business partners [8] Customer trust depends on a number of interpersonal and inter-organizational factors, such as the competence, integrity, honesty, and kindness company in customer mind. customer trust is the power of knowledge that every customer conclusions made by the customer product have objects it, attributes and benefits [9]. Mentions it bonding with consumers is a central problem in marketing strategies which fostering consumer confidence. [10] represent customer trust influence by few factors which used as a dimension, such as :1) Transparent, informed, honest, 2) The best quality products and services, products and services to meet expectations, 3 ) incentives align to employees customer trust and fulfil themselves, 4) Design collaboration, customers help design products individually and through the community, 5) Product comparison and advice, comparing competitor products honestly and comprehensive community, 6) Supply chain, all supply chain partners unite to build customer trust, 7) Advocacy or pervasive, all functions work to build customer trust furthermore.

\subsection{Image Corporate}

[11] defines a company's image corporate as a set of beliefs, ideas, and impressions that a person has toward an object. While [12]indicates that the company's image corporate is a picture of the overall impression made by the public's views or thoughts about the company. The Company's image corporate relate to the physical attributes and behaviour of the company, product innovation and service, and the impression of the communication quality of its employees in establishing relationships with customers. There are three important things related to image corporate that impression an object, the process of forming an image corporate, and a customer trusted source. Objects include people and companies that consist of a group of people. Image corporates formed by processing information that didn't a close possibility in the image corporate of the object from the receipt of information at any time. Amount of object customer trust dedicated source of information provides the basis for acceptance or rejection source of information. Sources of information come directly from companies and other parties directly. Corporate image corporate show impress objects against the company which formed by processing information every time from various reliable sources related information 
The type of research used descriptive and explanatory approach, practically there are two survey methods applied in the field study. The analytical method described in picture 1 where every variable analyzed and give positive relationship between an observed variable and the manifest variable. To collect data used a questionnaire instrument thus in the form of a questionnaire that will be distributed to PLN Bright prepaid electricity customers in seven (7) sub-districts in the Batam area. Data collection in field study used 2 methods for distributing questionnaires through the "Google docs" online survey site and distributing quesioners to respondents with reference to prepaid electricity customers. Characteristic of the population to collect the data used in this study are electricity customers oriented to households. The sampling technique in field study used "Proportional Sampling". In accordance with the analysis model described above, data processing and analysis using Structure Equation Model (SEM), how in processing data using the software analysis tool Lisrel 9.3 for Windows.

\section{Results and Discussion}

From the field study results more than 200 respondents obtained PLN Bright Batam customer profile in table 1 as follows,:

Table 1. Description of Respondents

\begin{tabular}{lll}
\hline information & amount of & $\%$ \\
\hline address & & \\
Batam Kota & 57 & 28,5 \\
Batu Aji & 34 & 17,0 \\
Bengkong & 13 & 6,5 \\
Lubuk Baja & 31 & 15,5 \\
Nongsa & 13 & 6,5 \\
Sagulung & 31 & 15,5 \\
Sekupang & 21 & 10,5 \\
Sex: & & \\
Pria & 85 & 42,5 \\
Wanita & 115 & 57,5 \\
education : & & \\
SD/SMP/SMA & 107 & 53,5 \\
D1/D3 & 11 & 5,5 \\
S1/S2 & 82 & 41,0 \\
age : & & \\
20-30 tahun & 69 & 34,5 \\
31-40 tahun & 101 & 50,5 \\
> 40 tahun & 30 & 15 \\
occupation: & & \\
Bisnis/Wiraswasta & 32 & 16,0 \\
Karyawan Swasta & 96 & 48,0 \\
PNS/BUMN & 11 & 5,5 \\
other & 61 & 30,5 \\
income : & & \\
< Rp 3.000.000 & 43 & 21,5 \\
3.000.000-5.000.000 & 73 & 36,5 \\
5.000.000-10.000.000 & 70 & 35,0 \\
>10.000.000 & 14 & 7,0 \\
\hline
\end{tabular}


In this study, the number of respondents who met the requirements for analysis was 200 and the total number of manifest variables is 19 , while the rule of thumb for the comparison number of samples to the number of indicators is 1:5[13].

According to [14]Validity testing compared to find capability the indicators like (latent variable) to measure the construct accurately. There are two ways to testing validity which checking the customer value of " $\mathrm{t}$ " and checking the high load the standard factor or $\lambda$ (Standardize loading factor).

After running LISREL program for each variable (NIPEL KEPERCAYAAN, CITRA) sequentially then known customer value of $\mathrm{t}$ and $\lambda$ of the indicators in each of the latent variables is above the critical customer value that is $>1.85$ for $t$ customer values and $>0.30$ for the customer value of $\lambda$. Except for indicator X3 for the latent variable Customer, Trust is the average critical limit that is equal to 0.87 and 0.64 this indicates that the indicator of each latent variable meets the criteria as a valid indicator to represent each latent variable that it represents. Reliability testing directly from LISREL output is looking by the customer value of $\delta$ for exogenous variables and $\varepsilon$ for endogenous variables. Behind the path diagram generated by LISREL to assessed the measurement error customer value of each indicator variable is very low, that is below $<0.30$. Indirect testing uses two parameters, consist of construct reliability and variance extract which is shown in table 2 as follows.

Table 2. Reliability Construct

\begin{tabular}{lcc}
\hline Variable latent & \multicolumn{2}{c}{ Parameter } \\
& CR & VE \\
\hline VALUE & 0,9 & 0,81 \\
TRUST & 0,5 & 0,68 \\
CORP IMAGE & 0,8 & 0,54 \\
\hline
\end{tabular}

From table 2 above described customer value of construct reliability, each variable above conform critical limit of $>0.5$. Whereas belong to variance extracted 3 the latent variable above the critical limit. Customer value (NIPEL) of 0.81 with construct reliability 0.79 and variance extract customer values not in include the critical limit, it means indicator variables have good measurement consistency through the latent variables represent it. As a comparison material by means of the results obtained reference journal [15] can be seen from table 3 as follows:

Table 3. R square

\begin{tabular}{lcc}
\hline Variable latent & \multicolumn{2}{c}{ Parameter } \\
& CR & VE \\
\hline VALUE & 0,9 & 0,81 \\
TRUST & 0,5 & 0,68 \\
CORP IMAGE & 0,8 & 0,54 \\
\hline
\end{tabular}

From table 2 above described customer value of construct reliability, each variable above conform critical limit of $>0.5$. Whereas belong to variance extracted 3 the latent variable above the critical limit. Customer value (NIPEL) of 0.81 with construct reliability 0.79 and variance extract customer values not in include the critical limit, it means indicator variables have good measurement consistency through the latent variables represent it. As a comparison material by means of the results obtained reference journal [15] can be seen from table 3 as follows: 
Table 4. R square

\begin{tabular}{lc}
\hline Latent variable & R square \\
\hline VALUE & 0.71 \\
IMAGE CORP & 0.65 \\
TRUST & 0.61 \\
\hline
\end{tabular}

From the reliability measurement results with three parameters of Customer Customer value (NIPEL), Image, Corporate and Customer Trust proven to reliable in each manifest variable. NIPEL variable even though the measurement error customer value is high $(0.71)$ in one of the manifest variables X5 but it balance high customer value of Construct Reliability and Variance Extract that is 0.79 and 0.81 so that the NIPEL and CUSTOMER TRUST variable is proven reliable, with two parameters: measurement error and extract variant above the critical limit but the Construct Reliability customer value is greater than the critical limit (0.79> 70 so that it remains reliable.

\section{Test Of Hypotheses}

Three research hypotheses are included in the structural equation as follows:

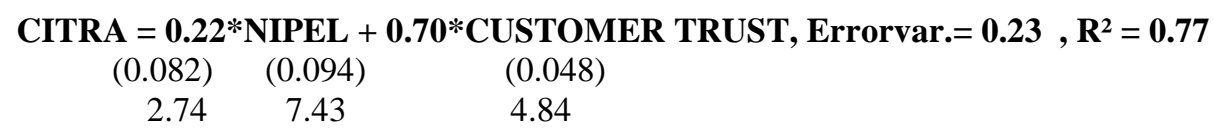

Research hypothesis testing by examine the relationship between latent variables such as equations and to test the relationship between latent variables. From each of these latent variables generate customer value of score Factor, note that the structural model is tested simultaneously

The following are the results of testing hypotheses:

\section{H1 : customer value has a positive effect to the Image Corporate}

With at customer value of 0.72 , the amount far above the critical limit, the influence is given by the Customer, Trust variable gives an effect of 0.22 on IMAGE CORPORATE, which is proven to significant.

\section{H2: customer trust has a positive effect to the image corporate}

From the equation formula above shows that the variable customer value of 0.74 is higher the critical limit. Coefficient customer value is 0.70 with a high $\mathrm{R}$ square validity customer value of 0.62 which means that the customer value of the Customer Customer value has a positive effect of 0.70 to Customer trust and the results obtained statistically significant then the latent variable Customer trust became valid and reliable. In SEM there are 3 suitability tests conducted, namely: overall model suitability testing: (Overall model fit)., testing suitable measurement model (fit model measurement) and testing confirm structural model (Structural model fit). Suitability testing of measurement models carries out in the previous section. Because it relates to Validity and Reliability. By running the LISREL program to test suitable the model, the last form of the Structural diagram is the fit model of the relationship between the latent variables in the following figure: 


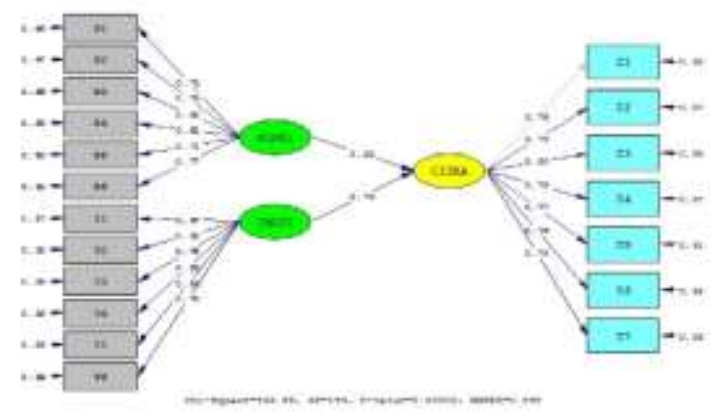

Figure 1. Structural Overall Model Fit

Testing the overall model using the Goodness of fit indices (GFI) indicator, GFI selected because an indicator commonly used in testing the overall another model as a comparison also used Normal fit index and comparative fit index (NFI) to obtained directly from the LISREL output, the customer value of each manifest variable will be presented in the table below:

Table 5. Goodness of Fit Indices

\begin{tabular}{lc}
\hline Overall model fit : & Measures \\
\hline Degrees of Freedom & 149 \\
NCP & 286.66 \\
RMSEA & 0.098 \\
ECVI & 2.6 \\
NFI & 0.95 \\
CFI & 0.96 \\
GFI & 0.81 \\
AGFI & 0.76 \\
\hline
\end{tabular}

Overall test results of the model are above the customer value of 0.80 except for the measurement model of latent variables Value and Customer, Trust against the Image Corporate indicator GFI $=0.81$ but still balanced with the customer value of NFI $=0.95$ and $\mathrm{CFI}=0.96$ overall model conformity. Overall the specified model has a level of compatibility with the manifest variables and the underlying latent variables. Indicates that the proposed model has a good level of conformity except for the relationship of manifest variables to the latent variable Image Corporate, but according to Ghozali, (2011) the GFI and NFI customer values above $>0.70$ are high enough. Thus the structure model specified has a high level of suitability. The indicator proposed the structure model in the path model that $\mathrm{R}$ square from the overall hypothesis producing 1 equation model, there is only one structural model proposed. In testing model hypothesis cut structural model to continue testing suitability the model construct.

This study provides several implications for existing new organizations that will apply information technology in general, especially with regard to the services corporate in largescale. This research use as a reference for developing literature both in the education sector and for practitioners in measuring the level of satisfaction PLN Bright customers in Batam. This research follow ing the footstep of several similar studies in the past that have sought to quantify the energy efficiency behavior that prepaid energy product engender, and the efficiency finding fall in line with the finding of these other studies. Unlike other studies that 
have tested regulated utility program. This study shows the benefits are maintained in competitive market. Seen though the PLN Bright Batam. Product could present a compelling case to be a transformational product in the energy marketplace. The most essential finding of the study is that prepaid electricity does have an energy efficiency benefits of approximately55.\% with an average $40 \%$ for non lite household, which constitute the great majority of household. The benefits in net of any reduction in consumption from disconnection. Energy efficiency stem from more engagement by the customer with his or her energy service. The PLN Bright Batam Has more frequent communication about his / her usage and the associated cost. More granular information and more real time information. But beyond that customer image not only provides deeper information; it enabled customer to relate his cost to his benefit in a timely and concrete financial transaction that makes the communication " more real".

\subsection{Implication of Finding}

The financial impact of this efficiency can be quite significant. An energy managers using approximately IDR 12583,37 000 per MWH per years and paying.IDR1467,28 per KWH. Would save IDR15436 per year for efficiency. By the way of example if all residential customers in Batam island switched to saving would be top approximately IDR 1 million per years. If all residential customers realized a 9,6\% efficiency benefits. Beside the energy saving, the efficiency could lower peak capacity requirement, meaning fewer expensive peaker-plant generator would need to be maintained in the generation stack for long term period. Beyond the energy and monetary saving approach can change the way people interact with their energy and manage their household. This engagement with energy and manage their household. This engagement with energy composition can yield new dynamic as we move into a distributed generation economy in which consumer of energy can also be producer of energy. The out model monthly billing arrangement will not continue to be sufficient in a new energy economy.

\subsection{Agenda For Future Research}

Suggestions for future research important because the respondents in study very homogeneous which observed only in one institution. We recommend for future research to develop and check the scope institutions or agencies that have extensive networks with other business models. The sample used is expect minimized according to the rule of thumb in Covariance basic SEM. By developing higher variables and analysis such as PLS or GESCA Analysis may have better implications? This study has several limitations that might influence the results of the research to do, among others: the limited number of respondents so that data cannot be tested simultaneously (single step). Although the results of the analysis produced will be the same but the resulting path diagram cannot describe model consisting consist structural models (2) limitations inherent in the data obtained through questionnaires, because of differences in the perception of the author with the respondents.

\subsection{Funding}

This research was funded by the 2017 Research and Technology Grant and implemented in February 2018. Research Funds implementation was based on the decision of the Ministry of Research, Technology and Higher Education Number SP DIPA-042.06.140151 / 62 0L8, dated December 5, 2017. 


\section{References}

[1] S. Suhartono, "a Comparative Study of Forecasting Models for Trend and Seasonal Time Series Does Complex Model Always Yield Better Forecast Than Simple Models," J. Tek. Ind., vol. 7, no. 1, pp. 22-30, 2005.

[2] M. M. Rahman, S. Hettiwatte, G. Shafiullah, and A. Arefi, "An analysis of the time of use electricity price in the residential sector of Bangladesh," Energy Strateg. Rev., vol. 18, pp. 183198, Dec. 2017.

[3] G. R. Telles Esteves, F. L. Cyrino Oliveira, C. H. Antunes, and R. C. Souza, "An overview of electricity prepayment experiences and the Brazilian new regulatory framework," Renew. Sustain. Energy Rev., vol. 54, pp. 704-722, Feb. 2016.

[4] G. D. Kortge and P. A. Okonkwo, "Perceived value approach to pricing," Ind. Mark. Manag., vol. 22, no. 2, pp. 133-140, May 1993.

[5] F. Tjiptono, Pemasaran Jasa. Yogyakarta: CV. Andi Offset, 2014.

[6] D. Woodruff and E. Gudova, Interview with David Woodruff: "Financial Market Governs. 2016.

[7] J. A. L. Sanchez, "Customer value (Perceived). In Wiley Encyclopedia of Management.," 2015.

[8] P. Kotler, "Kotler on...Management Decision," vol. 29, no. 2, 2011.

[9] L. G. Schiffman, H. Hansen, and L. Kanuk, Perilaku Konsumen. Edisi Kedua, Kedua. Jakarta: PT. Indeks Gramedia., 2007.

[10] M. Kilgour, "Marketing Management: An Asian Perspective.," Australas. Mark. J., vol. 14, no. 2, p. 52, 2006.

[11] O. Isaac Oladepo and O. Samuel Abimbola, Pemasaran Produk. Yudistira, 2014.

[12] M. J. Sirgy and J. E. Danes, "Self-Image/Product-Image Congruence Models: Testing Selected Models," vol. 9, no. 1, pp. 556-561, 1982.

[13] A. Kurniawan, L. Loekito, and S. Solimun, "Power Of Test Path Analysis and Partial Least Square Analysis," vol. 4, no. 3, pp. 112-114, 2016.

[14] J. Hair, Multivariate Data Analysis. Faculty Publications, 2009.

[15] V. Kumar and W. Reinartz, "Comparison between electrochemical noise and electrochemical frequency modulation measurements during pitting corrosion," J. New Mater. Electrochem. Syst., vol. 80, no. 2, pp. 36-38, 2016. 